\title{
Geophysical Identification of Hydrothermally Altered Structures That Favour Gold Mineralisation.
}

\section{${ }^{* 1}$ OHIOMA, J.O; ${ }^{2}$ ADEGBITE, J. T; ${ }^{3}$ EHILENBOADIAYE, J.I}

\author{
${ }^{1}$ Department of Physics, University of Benin, Benin City, Edo State, Nigeria \\ ${ }^{2}$ Department of Physics, University of Benin, Benin City, Edo State, Nigeria \\ ${ }^{3}$ Department of Physics, University of Benin, Benin City, Edo State, Nigeria \\ * Email of Corresponding author: ohioma.jerry.ohi@gmail.com
}

\begin{abstract}
This research study uses geophysical method (aeromagnetic) to identify hydrothermally altered structures which favour the inflow of hydrothermal fluid that usually brings about gold mineralisation in Egbe-Isanlu Schist Belt Area, North Central Nigeria. The application of data enhancement filtering algorithm such as reduction to the pole to the magnetic data aided in mapping of various hydrothermally altered structures that may favour gold mineralisation. The interpretation of the aero data set has enhanced a lot of hydrothermally altered structures that trend northeast-southwest(NE-SW). A number of hydrothermally altered structures are seen. Therefore the areas that are hydrothermally altered are potential sites for gold mineralisation, most importantly those areas that lie within or adjacent to major faults around Odogbe and Okolom in the North Central portion of the study area. Similarly, regions around Egbe in the western edge are suspected to be mineralized zones. The results obtained in this research study demonstrated that the geophysical tools adopted are powerful and effective means for gold mineral exploration. This method is unique because it is non-invasive which prevented any environmental degradation and it enhances the coverage of very large area. (C) JASEM
\end{abstract}

https://dx.doi.org/10.4314/jasem.v21i6.8

Keywords: Aeromagnetic Data; Isanlu; Structures; Gold Mineralisation; Hydrothermally Altered.

The regional setting in Nigeria is very similar to the Ashanti and Sefwi systems in nearby Ghana, with gold being found in most parts of supracrustal (Schist) belts in the northwest and southwest. Though the precious metals are not essential for industrialisation, they are a high source of foreign exchange and their exploitation to a large scale promotes the establishment of ancillary industries.

Regionally, it was noticed by Woakes and Bafor (1984) that primary gold deposits are associated with some Schist belts of northwest and southwest Nigeria (e.g. Isanlu, Maru, Anka, Kushaka) but not with others (e.g. Wonaka, Karaukarau, Iseyin-Ogun River) and each covers several thousand square kilometres. Aero-survey measurements are usually made from low-flying airplanes flying along closely spaced, parallel flight lines. Additional flight lines are flown in the perpendicular direction to assist in data processing. These large volumes of measurements then are processed into a digital aerodata map. Aeromagnetic survey is one of the most important tools used in modern geological mapping and mineral exploration. The principle is similar to magnetic survey carried out with a hand-held magnetometer but enables larger areas of the Earth's surface to be covered quickly for regional reconnaissance; this is needed because most of the Schist belts in which gold is found in Nigeria cover several thousand square kilometres. The aircraft typically flies in a grid-like pattern with height and line spacing determining the resolution of the data (and cost of the survey per unit area).

In order to explore for various natural potentials within the Nigeria landmass, there is need to develop a roadmap to investigate the various zones that might host valuable minerals such as gold within the country. With the objective to delineate the hydrothermally altered zones of sheet 225 (Isanlu); part of the Schist belt of Nigeria, this study attempts to use aeromagnetic data to delineate the various structures that favour hydrothermal gold mineralization in the area.

Hydrothermal mineral deposits are those in which hot water serves as a concentrating, transporting and depositing agent through faults (structures) to the earth's surface. Hydrothermal mineral deposit any concentration of metallic minerals formed by the precipitation of solids from hot mineral-laden water (hydrothermal solution). The solutions are thought to arise in most cases from the action of deeply circulating water heated by magma. Other sources of heating that may be involved include energy released by radioactive decay or by faulting of the Earth's crust. These waters may deposit their dissolved minerals in openings in the rock, thus filling the cavities, or they may replace the rocks themselves to form so-called replacement deposits. Both processes may occur simultaneously, the filling of an opening

\footnotetext{
*Corresponding authorEmail: ohioma.jerry.ohi@gmail.com
} 
by precipitation accompanying the replacement of the walls of the opening.

Deposition can be caused by boiling, by a drop in temperature, by mixing with a cooler solution or by chemical reactions between the solution and a reactive rock. Hydrothermal deposits are never formed from pure water, because pure water is a poor solvent of most ore minerals. Rather, they are formed by hot brines (water containing salts), making it more suitable to refer to them as products of hydrothermal solutions.

The water in a hydrothermal solution can come from any of several sources. It may be released by a crystallizing magma; it can be expelled from a mass of rock undergoing metamorphism; or it may originate at Earth's surface as rainwater or seawater and then trickle down to great depths through fractures and porous rocks, where it will be heated, react with adjacent rocks and become a hydrothermal solution. Irrespective of the origin and initial composition of the water, the final compositions of all hydrothermal solutions tend to converge, owing to reactions between solutions and the rocks they encounter. Most gold deposits are sourced from metamorphic rocks because it is thought that the majority are formed by dehydration of basalt (mafic rock) during metamorphism.
The main objective of this study is to employ the use of areomagnetic data interpretation to detect structures that might have been altered magnetically due to the intense heat originating from hudrothermal fluid.

Geology and location of the study area: Precambrian Basement Complex, Younger Granites and Sedimentary Basins makes up the rock groups in Nigeria (Kogbe, 1989). The study area is a part of the Schist belt of the Precambrian Basement Complex of North Central Nigeria (Figure 1). The Schist Belts comprise low grade, meta-sediment-dominated belts which are best developed in the western half of Nigeria. These belts are considered to be Upper Proterozoic supracrustal rocks which have been infolded into the migmatite-gneiss-quartzite complex. Most metallogenetic features of the Schist belts are relevant to these problems; the apparent absence of subduction related mineral deposits; the distribution of primary gold occurrences in some belts but its marked absence in others may indicate that they do not represent a single supracrustal sequence.

The study area is located within $8^{0} 00^{\prime} 00^{\prime \prime} \mathrm{N}$ to $8^{0} 30^{\prime} 00^{\prime} \mathrm{N}$ and $5^{0} 30^{\prime} 00^{\prime \prime} \mathrm{E}$ to $6^{0} 00^{\prime} 00^{\prime \prime} \mathrm{E}$ (Isanlu Sheet 225).

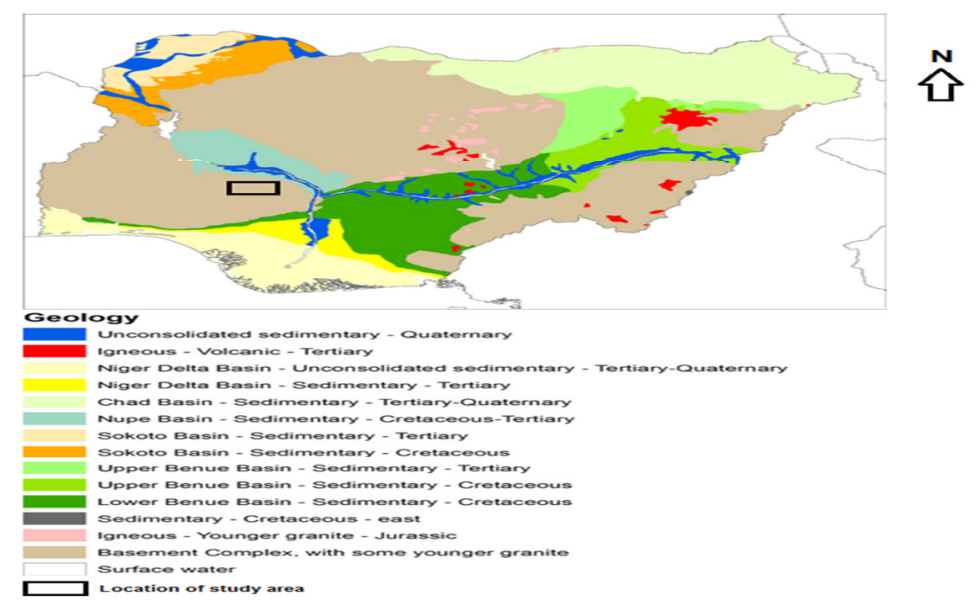

Fig 1:Geology of Nigeria at 1:5 million scale. Developed from USGS map (Persits et al. 2002).

Methodology: The aeromagnetic data analysed for this study was obtained from Nigerian Geological Survey Agency. The data are part of the nationwide aero geophysical survey programme sponsored by the Nigerian geological survey agency.

The data acquisition was carried out by fixed wing aircraft. Total line kilometers of 36,500 were covered in the survey. Magnetic gradient was the measured parameter.The data were acquired along a series of
NW-SE flight lines with a spacing of 500 meters and an average flight elevation of about 100 metres while tie lines occur at about 2000 metres interval in the NE-SW direction. The geomagnetic gradient was removed using International Geomagnetic Reference Field (IGRF). The magnetic data were sampled at a rate of $0.1 \mathrm{sec}$ using the Scintrex Cesium SC-2 (proton precession magnetometer). 
Geophysical processing consisted of gridding magnetic airborne survey data using a variety of software. The major software used to process and enhance the data is the Geosoft (Oasis Montaj). Other geophysical software was used to enhance the data in a variety of formats such as Golden Software Surfer 10.

Airborne magnetic data are often used as a powerful tool to aid mineral exploration. This is achieved by visual inspection of the map.

MAGMAP filtering utilities were then applied to the magnetic grids to enhance the data for easy interpretation. The filters in MAGMAP are a range of linear and nonlinear mathematical algorithm which selectively enhances the anomalies due to one group of geological source relative to anomalies due to other group of geological source (Milligan and Gunn, 1997). The mathematical enhancement techniques are complemented by a range of imaging routines such as the step by step procedure in MAGMAP which can be specified to visually enhance the effects of selected geological sources (Telford et al., 1990).

In this project the MAGMAP filter used in enhancing the magnetic data is the reduction to the pole.

\section{RESULTS AND DISCUSSION}

The results from the processed and enhanced magnetic data were developed into different maps. These maps are interpreted below and hydrothermal altered structures are then mapped from the maps. The interpreted altered structures are path finders for gold mineralisation zones in Egbe-Isanlu Schist belt, North central Nigeria.

Different colours are used in airborne magnetic maps to indicate the amount of magnetic minerals (magnetite, pyrrhotite) in different rock formations. Red colour is used to indicate areas with high content of magnetic minerals and deep blue colour indicates areas with low content of magnetic minerals.

Total Magnetic Intensity (TMI) Map: As the name implies, the total magnetic intensity is the magnetic field that is observed in a particular location, it is a combination of the Earth's magnetic field and the field produced by magnetic bodies that are in the subsurface. Figure 2 is the Total Magnetic Intensity (TMI) map of the surveyed area. From the map, the high magnetic intensity regions are actually areas with low magnetic intensities and the low magnetic intensity regions are actually areas with high magnetic intensities.
This misrepresentation is called directional noise that is observed in low magnetic latitude areas due to the inclination of the Earth's magnetic field at this low latitude, this problem is corrected by reducing the total magnetic intensity to the pole where the Earth's magnetic field is vertical. This directional noise problem if not corrected can cause data misinterpretation, hence there was the need for reducing to the pole for easy interpretation of the results.

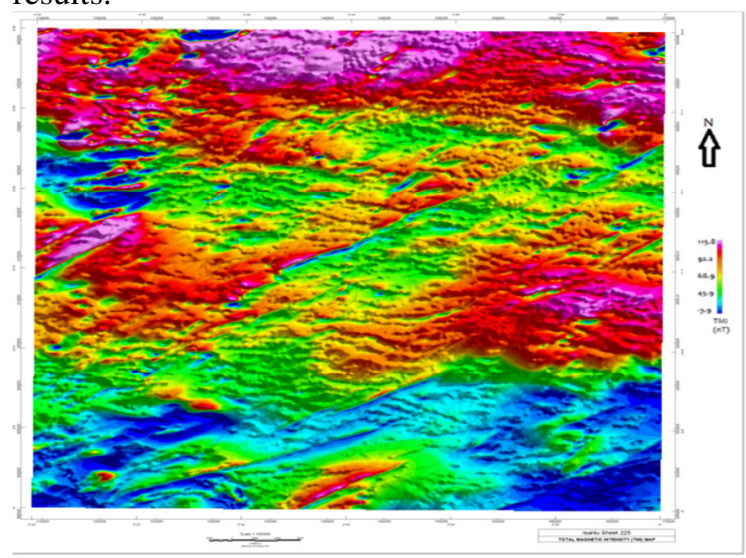

Fig 2: Total magnetic intensity (TMI) map of Isanlu sheet 225

Reduction to Pole:Asymmetric anomalies (caused by the non-vertical inducing field) are difficult to relate to the source bodies or geometry causing the anomalies in magnetic survey (Murphy, 2007).

Reduction to the pole is the process of converting the magnetic field developed by magnetic bodies from the magnetic latitude where the Earth's field is inclined, to the field at the Earth's magnetic pole, where the inducing field is vertical. When the Earth's field is inclined, magnetic anomalies due to induction have forms that are asymmetrically related to their sources as this is noticed in Figure 3 where high magnetic intensity regions were seen as low magnetic intensity region and the reverse, but when the inducing field is vertical, the induced anomalies are directly over their sources. This is seen between the TMI (Figure 2) and the RTP map (Figure 3) that regions with high magnetic intensities in the TMI map are recording low magnetic intensities in the RTP map and vice versa. Reduction-to-the-pole (RTP) is a useful and effective operation designed to transform a total magnetic intensity (TMI) anomaly caused by an arbitrary source into the anomaly that this same source would produce if it were located at the pole and magnetized by induction only (Li, 2008). 
From the RTP map below, the structures labelled F1, F2, F3, F4 and F5 are the structures that might have served as conduits for hydrothermal fluid because these structes tend to exhibit moderate to low magnetic susceptibility signatures which might have been resulted from the destruction of magnetite due to the heat associated with the inflow of hydrothermal fluid.

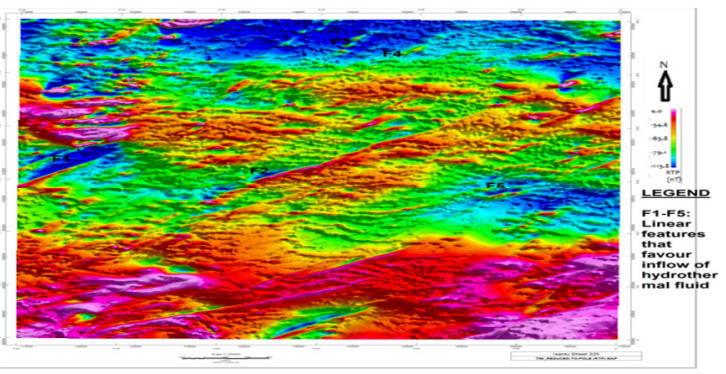

Fig3: Reduced to pole (RTP) map of TMI of Isanlu sheet 225

Interpreted hydrothermally altered structural map: Airborne magnetic surveys are effective in delineating major structures which may control the locations of hydrothermal gold deposits and also in detecting magnetic lows or "flat zones" resulting from the destruction of magnetite by hydrothermal alteration (Irvine and Smith 1990).

Structures are interpreted from the aero-magnetic data where they terminate as a series breaks in smooth magnetic signature serve as marker units within the stratigraphy (Murphy,2007)

From the magnetic maps shown above, the interpreted structural map of the study area is deduced as shown below in Figure 4. It is seen that the study area has a lot of structurally complex features. Areas that have complex structures are known to correlate with gold deposits; therefore areas with higher structural complexity are likely zones of mineralisation (Zlotnikov, 2012).

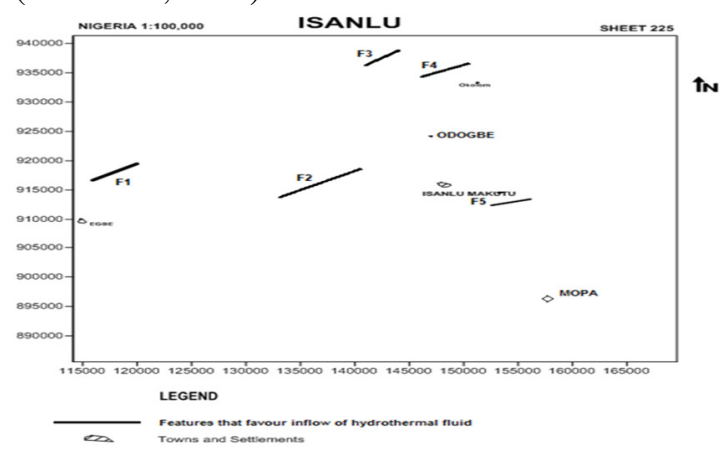

Fig 4: Interpreted hydrothermally altered structural map from the aero-magnetic data of Isanlu sheet 225
Conclusion: Structural characterisation and hydrothermal alteration zones which are favourable for gold mineralisation have been made possible via the use of aero-geophysical survey method.

The areas that are hydrothermally altered are potential sites for gold mineralization, most importantly those areas that lie within or adjacent to faults around Okolom in the north-central portion of the study area. Similarly, regions around Egbe in the western edge are suspected to be mineralized zones.

Acknowledgement: The Authors appreciate the help from Nigerian Geological Survey Agency for making the Data available for this study.

\section{REFERENCES}

Irvine, RJ; Smith, MJ (1990). Geophysical Exploration for epithermal gold deposits. Journal of Geochemical exploration vol 316 pp.315-416

Kogbe, CA (1989). Review of the basement geology of southwestern Nigeria. In: Geology of Nigeria.Elizabethan publishing Company Lagos, pp. 41-58 (originally written by Rahman, M. A., 1976).

$\mathrm{Li}, \quad \mathrm{X}$ (2008). Magnetic reduction-to-the-pole at low latitudes.Fugro Gravity and Magnetic Services. Houston, USA.: Fugro. Pp. 85

Milligan, PR; Gunn, PJ (1997). Enhancement and presentation of airborne geophysical data. AGSO Journal of Australian Geology and Geophysics, 17(2), 63-75.

Murphy, BSR (2007). Airborne geophysics and the indian scenario. J. Ind. Geophysics

Union, 11(1): pp. 1-28.

Persits, F; Ahlbrandt, T; Tuttle, M; Charpentier, R; Brownfield, M; Takahashi, K (2002). Map showing geology, oil and gas fields and geologic provinces of Africa, Ver 2.0. USGS Open File report 97-470 A.

Telford, WM; Geldart, LP; Sheriff, RE (1990). Applied Geophysics. Cambridge. ICRU (1994). Gamma ray Spectrometry in the Environment, ICRU Report 53. International Commission On Radiation Units And Measurements, Bethesda, USA. pp. 22-88

Woakes, M; Bafor, BE (1984). Primary gold mineralization in Nigeria, pp. 661-671

Zlotnikov,D (2012). Automated Image Analysis Targets Ground Selection; Application of Aero-magnetic Structural Analysis Techniques for Greenfields Gold Exploration 